\title{
Do Fast Food Milieus Influence the Eating Behaviors and BMI of Adolescents?
}

\author{
Riya Malushte ${ }^{1}$, Sammita Jadhav ${ }^{2}$, Radhika Hedaoo ${ }^{2, *}$ \\ ${ }^{1}$ Symbiosis School of Biological Sciences, Symbiosis International (Deemed University), Pune, India \\ ${ }^{2}$ Symbiosis Institute of Health Sciences, Symbiosis International (Deemed University), Pune, India
}

Received August 27, 2021; Revised October 26, 2021; Accepted November 11, 2021

\begin{abstract}
Cite This Paper in the following Citation Styles
(a): [1] Riya Malushte, Sammita Jadhav, Radhika Hedaoo, "Do Fast Food Milieus Influence the Eating Behaviors and BMI of Adolescents?," Food Science and Technology, Vol. 10, No. 1, pp. 1 - 8, 2022. DOI: 10.13189/fst.2022.100101.
\end{abstract}

(b): Riya Malushte, Sammita Jadhav, Radhika Hedaoo (2022). Do Fast Food Milieus Influence the Eating Behaviors and BMI of Adolescents?. Food Science and Technology, 10(1), 1 - 8. DOI: 10.13189/fst.2022.100101.

Copyright $(2022$ by authors, all rights reserved. Authors agree that this article remains permanently open access under the terms of the Creative Commons Attribution License 4.0 International License

\begin{abstract}
Background: The nutrition transition has commercialized fast foods worldwide despite of the evinced health hazards. This necessitates a scientific appraisal of the factors leading to fast food consumption and its associated Body Mass Index (BMI) status amongst adolescents. Objectives: The objectives of the present study were to assess the pattern of fast food consumption, factors affecting the consumption, and correlate the fast foods intake with the BMI of adolescents (16-19 years). Methodology: This cross-sectional study was conducted on a randomly selected sample of 219 adolescents across the gender, pursuing higher secondary education in an urban city of India. A structured questionnaire was administered on understanding consumption pattern and their reasons for consumption of fast foods. Anthropometric measurements included height (cms), weight (kgs) and BMI. Descriptive statistics, spearman correlation, and factor analysis method were used for statistical analysis. Results: $14 \%$ and $24 \%$ of adolescents consumed fast foods once a day and three to four times a week respectively. Sweets and confectionary, burger, pizza, fried snacks, dairy desserts, and high fat sandwiches consumption showed a positive correlation with BMI $(\mathrm{p}<0.05)$. Factor analysis indicated taste and advertising of the fast foods as the most influencing factors which accounted for $17.56 \%$ variance followed by $13.62 \%$ variance shown by affordable pricing, branding, and easy availability of fast foods. Peer influence and comforts eating showed a variance of $11.38 \%$. Limited time availability and quick service indicated $10.06 \%$ whereas ambiance, food product quality showed $8.28 \%$ variance correspondingly. Conclusion: The factors recognized
\end{abstract}

make a supplication for nutrition education interventions for adolescents.

Keywords Fast Food Intake, Body Mass Index, Adolescents, Junk Foods, HFSS Foods, Eating Behavior

\section{Introduction}

Fast foods have become an integral part of diets particularly for the millennial youth of India who makes up $19 \%$ of the Indian population according to the Census report of India [1].

With an increase in disposable incomes and the advent of global food joints inflowing the Indian food market, India today ranks amongst the top ten fast-food per capita expenditure figures suggestive of the changing dietary patterns among adolescents as reported by Mulla et al.[2]. World Health Organization defines fast foods as "Foods that can be prepared quickly and easily and are sold in restaurants and snack bars as a quick meal or to be taken out" [3]. This dietary shift witnessed from traditional eating practices towards modern foods has augmented the consumption of processed foods and ready-to-eat foods especially junk foods.

The Indian Dietary Guidelines [4] defines "Junk foods as food that contains little or no protein, vitamin or minerals however is rich in salt, fat, and energy". The nutritional analysis conducted by Johnson et al [5] suggested that such junk foods are characteristically energy-rich and dense in fats, sugar, salt, Trans fats, and 
saturated fats and are also termed as High Fat, Sugar, Salt (HFSS) foods.

Snacks like burgers containing fried patties, pizzas containing highly refined flour, unhealthy fats, chips, sugar-sweetened beverages, Indian deep fried snacks like samosa, pakoras, etc. are included under the junk food category [6]. When consumed habitually at the expense of nutrient-dense foods, they create nutritional imbalances in the body as they lack the essential micronutrients like vitamins, minerals, and dietary fiber.

The marketing and promotional tactics adopted by the fast foods and beverage industry lure the young generation into uncontrolled feasting of these foods. The major dietary behaviors observed among adolescents are skipping meals, restricted eating, over-eating and preference of dining at fast food joints or ordering from the fast food takeaways [7]. These practices mask the health threat of nutrition related non-communicable diseases such as obesity, diabetes, and cardio-vascular diseases gaining prominence amongst adolescents [8]. The urban adolescents in the age group of 16-19 years (i.e. late adolescence) have demanding academic activities for a long period of time and often found to have faulty eating practices due to busy academic schedules and time limitations. Excessive fast food intake which compromises the nutritional quality of diets is linked with higher body mass index and risk of obesity and related health complications for adolescents reported by Zalewska et al. [9].

There have been quite a few studies measuring the fast food intake among adolescents in India; however, there is a paucity of data available on the determinants of fast food consumption assessed among Indian teenagers.

The novelty of the research lies in presenting these multi-facet factors extracted through factor analysis which well-defined the variability of the factors contributing towards fast food consumption in an urban cosmopolitan city of India. Conclusions derived from the study could serve as a piece of evidence for nutrition policymakers to come up with interventions for tackling the health implications of fast food consumption among teenagers. Also, in view of the established excess energy intake and associated weight gain, the present study focused on assessing the factors leading to high consumption of fast foods and correlates the intake with the body mass index of adolescents.

\section{Methodology}

This cross-sectional, observational study was conducted among adolescents, males, and females $(n=219)$ in the age group of 16-19 years selected through a random sampling method. The study settings were co-educational coaching classes offered to students pursuing higher secondary education.

\section{Tools and techniques of data collection:}

Kuppuswamy socio-demographic scale, 2016 [10] was used to collect data on the education of the parents, total family income, and occupation of the parents through scores allotted on socio-economic status. Based on the total score calculated on the above-mentioned parameters, the family is positioned in the socioeconomic class as upper class (score between 26 and 29), upper-middle (scores between 16 and 25), lower-middle (scores between 11 and 15), upper-lower (scores between 5 and 10) and lower class (scores between below 5).

Anthropometric data on height in centimeters using seca stadiometer, weight in kilograms using digital weighing scale, and body mass index $\mathrm{Z}$ score were calculated using WHO Anthroplus software. Semi-quantitative food frequency questionnaire on various popular fast foods was administered to adolescents in a class room setting to obtain information on the frequency of fast foods. Questionnaire by Alfaris et al, [11] was referred and a structured questionnaire was formulated. The questionnaire was checked for its content validity with the help of one nutrition expert and one biostatistician who independently checked and evaluated the questions for relevance. All the questions were retained in the questionnaire. The questionnaire was checked for face validity by pretesting on a sample of adolescents $(n=10)$. The questionnaire was well understood by the participants and no questions were modified. Each item of the questionnaire had Likert scale responses categorized as $3=$ most influencing factor, $2=$ moderately influencing factor, and $1=$ least influencing factor. The questionnaire was administered in class room setting, in groups, by authors.

\section{Statistical Analysis}

The data were entered and analyzed through Statistical Package for Social Sciences (SPSS) version 20.07 (SPSS Inc., USA), using descriptive statistics such as frequencies, mean and standard deviation. Kolmogorov-Smirnov test was used to establish normality of the continuous data using SPSS software. It was found that the data were not normality distributed $(p<0.005)$ and hence non-parametric tests were used for statistical analysis.

The factor analysis method was used to identify the various factors affecting fast food consumption using the principle component analysis technique. Through factor analysis, the construct validity of the questionnaire was established. The suitability of using factor analysis and adequacy of the sample was assessed using Kaiser-Meyer-Olkin (KMO) test and Bartlett's test of sphericity. Factors showing an eigenvalue of $>1$ for the scree plot were considered. Spearman correlations were applied to observe the association between fast-food consumption and body mass index, with a 95\% confidence limit $(\mathrm{p}=<0.05)$. 


\section{Results}

The socio-demographic characteristics of the study population are given in Table 1. It was observed that participants belonged to the upper middle-income group. Majority of the adolescents belonged to the nuclear family (73.50\%). Around $49.50 \%$ of adolescents had normal BMI, while $14.00 \%, 17.50 \%$ and $19.00 \%$ were underweight, overweight, and obese respectively.

Table 2 indicates the frequency of fast food consumption and money spent on buying fast foods by adolescents. It was observed that $24.00 \%$ of adolescents consumed fast foods at least 3-4 times a week. It was observed that $35.90 \%$ of adolescents spent more than 1000 INR on buying fast foods per month.

Table 3 shows the preferred place, time, and frequency of fast foods consumed by adolescents. It was observed that the popular global fast food joints were preferred by $41.50 \%$ of adolescents. The preferred time was evening as mentioned by $36.50 \%$. The most popular fast food preferred by $29.00 \%$ of adolescents was Burger, followed by Pizza enjoyed by $19 \%$ and Indian fried snacks, ice creams milkshakes liked by $15.00 \%$ of adolescents.

Table 1. Socio-demographic and anthropometric details of adolescents $(n=219)$

\begin{tabular}{|c|c|}
\hline \multicolumn{2}{|c|}{ Socio-demographic characteristics } \\
\hline Mean Age & $16.55 \pm 1.00$ \\
\hline Income Group & Upper middle income group \\
\hline Males (n) & $104(52.00 \%)$ \\
\hline Females (n) & $96(48.00 \%)$ \\
\hline Joint Family (n) & $59(26.50 \%)$ \\
\hline Nuclear Family (n) & $160(73.50 \%)$ \\
\hline Weight (kgs) & $56.85 \pm 9.76$ \\
\hline Height (cms) & $159.80 \pm 8.52$ \\
\hline BMI (Mean) & 22.23 \\
\hline Underweight & $31(14.00 \%)$ \\
\hline Normal weight & $108(49.50 \%)$ \\
\hline Overweight & $38(17.50 \%)$ \\
\hline Obese & $42(19.00 \%)$ \\
\hline
\end{tabular}

Table 2. Frequency of fast food consumption and money spent on buying by adolescents

\begin{tabular}{|c|c|c|c|c|c|}
\hline \multicolumn{7}{|c|}{ Frequency of fast food consumption (n=219) } \\
\hline \multirow{2}{*}{$\begin{array}{c}\text { Frequency of Fast food } \\
\text { consumption }\end{array}$} & Almost daily & $\begin{array}{c}1-2 \text { times per } \\
\text { week }\end{array}$ & $3-4$ times a week & Once a month & Rarely \\
\cline { 2 - 6 } & $14.00 \%$ & $60.00 \%$ & $24.00 \%$ & $2.00 \%$ & $0.00 \%$ \\
\hline \multicolumn{7}{|c|}{ Pocket Money spent on buying fast foods per month by adolescents (n=219) } \\
in INR & $100-250$ & $250-500$ & $500-1000$ & $>1000$ \\
\hline$<50$ & $50-100$ & $28.00 \%$ & $15.00 \%$ & $11.00 \%$ & $35.90 \%$ \\
\hline
\end{tabular}

Table 3. Behaviour related to frequency, place and time preference for fast-food consumption

\begin{tabular}{|c|c|c|c|c|c|}
\hline Preferred Place & Percentage & Preferred Time & Percentage & Preferred Food & Percentage \\
\hline $\begin{array}{c}\text { Popular global fast food } \\
\text { joints }\end{array}$ & $41.50 \%$ & Breakfast & $3.00 \%$ & Burger varieties & $29.00 \%$ \\
\hline College/school canteens & $31.00 \%$ & Mid-morning & $5.00 \%$ & Pizza varieties & $19.00 \%$ \\
\hline Street food Joints & $16.50 \%$ & Lunch & $15.00 \%$ & $\begin{array}{c}\text { Fried snacks like French } \\
\text { fries, chips, pakoras }\end{array}$ & $15.00 \%$ \\
\hline Take away & $7.50 \%$ & Evening & $36.50 \%$ & $\begin{array}{c}\text { Sandwiches (grilled and } \\
\text { sweet varieties) }\end{array}$ & $13.00 \%$ \\
\hline Local restaurants & $3.00 \%$ & Dinner & $38.50 \%$ & Ice-creams and desserts & $15.00 \%$ \\
\hline $\begin{array}{c}\text { Branded five-star } \\
\text { restaurants }\end{array}$ & $0.50 \%$ & No specific time & $2.00 \%$ & Soft drinks & $10.00 \%$ \\
\hline
\end{tabular}


Table 4. Spearman's correlation between Fast Foods item consumption and Body mass index (BMI)

\begin{tabular}{|c|c|c|c|}
\hline & Food items & Correlation coefficient & P-Value \\
\hline \multirow{4}{*}{$\begin{array}{c}\text { Body Mass Index } \\
\text { (BMI) }\end{array}$} & Burgers & 0.66 & 0.003 \\
\cline { 2 - 4 } & Grilled cheese and sweet Sandwiches & 0.44 & 0.005 \\
\cline { 2 - 4 } & Fried snacks like French fries, chips & 0.66 & 0.003 \\
\cline { 2 - 4 } & Sweets and confectionary items & 0.71 & 0.002 \\
\cline { 2 - 4 } & Dairy-based desserts such as Ice creams and milkshakes & 0.66 & 0.002 \\
\hline
\end{tabular}

Table 5. Factors categorized as most, moderate, and least influencers affecting buying behavior towards fast foods among adolescents ( $\mathrm{n}=219$ )

\begin{tabular}{|c|c|c|c|c|}
\hline S.No & $\begin{array}{c}\text { Factor affecting buying behavior } \\
\text { among adolescents }\end{array}$ & $\begin{array}{c}\text { Most influencing } \\
\text { Aspect }\end{array}$ & $\begin{array}{c}\text { Moderately influencing } \\
\text { aspect }\end{array}$ & $\begin{array}{c}\text { Least influencing } \\
\text { aspect }\end{array}$ \\
\hline 1. & Taste of the food & $58.50 \%$ & $37.00 \%$ & $4.50 \%$ \\
\hline 2. & Food product quality & $5.00 \%$ & $2.00 \%$ & $93.00 \%$ \\
\hline 3. & Comfort eating & $30.00 \%$ & $48.50 \%$ & $21.50 \%$ \\
\hline 4. & Branding & $36.50 \%$ & $32.00 \%$ & $22.50 \%$ \\
\hline 5. & Advertising and marketing & $55.00 \%$ & $23.00 \%$ & $22.00 \%$ \\
\hline 6. & Affordable pricing & $54.50 \%$ & $23.50 \%$ & $70.00 \%$ \\
\hline 7. & Peer Influence & $28.00 \%$ & $2.00 \%$ & $20.00 \%$ \\
\hline 8. & Ease of availability \& convenience & $72.00 \%$ & $10.00 \%$ & $42.00 \%$ \\
\hline 9. & Ambiance & $22.00 \%$ & $36.00 \%$ & $50.00 \%$ \\
\hline 10. & Quick Service & $20.00 \%$ & $30.00 \%$ & $81.00 \%$ \\
\hline 11. & Nutritional information & $10.00 \%$ & $9.00 \%$ & $15.00 \%$ \\
\hline 12. & Time limitations and ease of & $75.00 \%$ & $10.00 \%$ & $50.00 \%$ \\
\hline 13. & consumption & $20.00 \%$ & $30.00 \%$ & \\
\hline
\end{tabular}

Table 6. Factor Analysis showing factors affecting fast food consumption

\begin{tabular}{|c|c|}
\hline Components & Variance in percentage $(\%)$ \\
\hline \multicolumn{2}{|c|}{ Component 1} \\
\hline Taste of the fast foods & \multirow{2}{*}{17.56} \\
\hline Advertising of the fast foods & \\
\hline \multicolumn{2}{|c|}{ Component 2} \\
\hline Affordable pricing & \multirow{3}{*}{13.62} \\
\hline Branding and promotion & \\
\hline Easy availability and convenience & \\
\hline \multicolumn{2}{|c|}{ Component 3} \\
\hline Peer influence & \multirow{2}{*}{11.38} \\
\hline Comfort eating & \\
\hline \multicolumn{2}{|c|}{ Component 4} \\
\hline Limited Time & \multirow{2}{*}{10.06} \\
\hline Quick service & \\
\hline \multicolumn{2}{|c|}{ Component 5} \\
\hline Ambience & \multirow{2}{*}{8.28} \\
\hline Food product quality & \\
\hline
\end{tabular}

Table 4 presents the spearman's rank-order correlation applied to determine the association between BMI z scores and the various fast foods consumed. Sweets and confectionary intake was strongly correlated with BMI. There was a moderate correlation observed between consumption of burgers, fried snacks like French fries, chips, dairy based desserts such as ice-creams, milkshakes, and grilled cheese sandwiches, and sweet sandwiches such as chocolate sandwiches and BMI.

Table 5 presents the factors affecting buying behavior of 
adolescents. It was observed that the taste of food was mentioned as the most influencing factor by $58.50 \%$ of adolescents. Advertising and marketing and affordable pricing were found to be the most influencing factor by $55.00 \%$ and $54.50 \%$ adolescents respectively. Time limitation and ease of consumption were reported by $75.00 \%$ of adolescents as the most influencing factor.

The factor analysis presented five important factors as components in the principal factor analysis which influenced fast-food consumption as described in Table 6. Figure 1 depicts the scree plot showing the factors extracted through principal component analysis.

The most important factors were the taste and advertising of the fast foods which accounted for $17.56 \%$ of the variance. The second component included affordability and pricing, branding and availability of fast foods which showed the variance of $13.62 \%$. The third component had peer influence and comfort eating which showed $11.38 \%$ variance, followed by limited time availability, quick service with $10.06 \%$ variance. The last component had ambience of the place where fast food is served and food product quality showing $8.28 \%$ variance.

\section{Scree Plot}

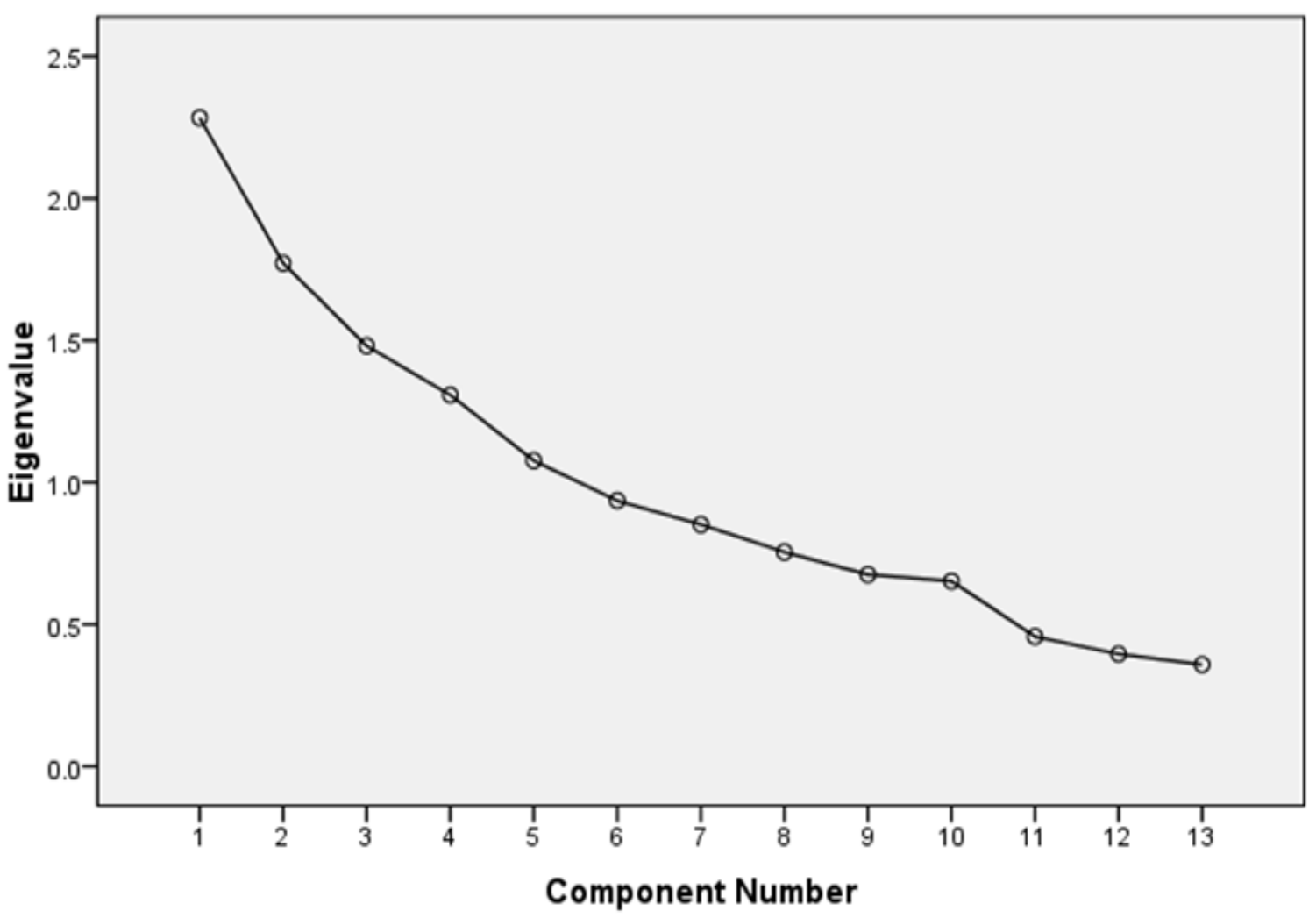

Figure 1. The scree plot showing the factors extracted through principal component analysis 


\section{Discussion}

The inclination towards fast food feasting especially junk food consumption has intensified in adolescents due to rapid urbanization and globalization in India. Understanding of the determinants of this indulgent behaviour is imperative to bring a change in the eating behaviors of adolescents. The present study observed the consumption trend of fast foods especially junk foods among adolescents and also identified the leading factors affecting the fast food consumption among adolescents. No significant difference in the frequency of fast foods consumed across the gender was observed. It was observed that the top six fast-foods consumed were burgers, pizza, Indian fried snacks, savory and sweet sandwiches, ice creams and milkshakes. It was observed that $24 \%$ of adolescents consumed fast foods more than 4 times a week and $14 \%$ consumed fast foods almost daily. Similar results were obtained in a study by Joseph et al. [12] reporting a daily fast-food consumption of $14 \%$ among high school boys of Mangalore city, India. Few other Indian studies have observed a rising trend of frequent fast food consumption among youngsters [13].A good socioeconomic status could be one of the reasons for the substantial sum of pocket money (> 1000 INR) spent on buying fast foods. Similar results were obtained in another Indian study in which high socio-economic status was found to be a dominant variable in fast food intake as investigated by Vaida [14]. It was observed that popular global fast food joints were the preferred place by $41.5 \%$ of adolescents. Czoli et al. [15] cogitated the extensive advertising and marketing done by the global food joints could be one of the reasons for the high preference of fast foods observed among adolescents. It was observed that the constant exposure to advertising has been found to be a prominent factor leading to fast-food consumption as found by Molenaar et al. [16]. Fast foods were preferred as evening snacks and dinner options by $36.5 \%$ and $38.5 \%$ adolescents respectively. The probable reason could be the leisure time after the academic engagements throughout the day. Similar results were found in another Indian study by Shree et al. [17] conducted on medical students which revealed that $48.3 \%$ students were taking fast foods as an alternative to dinner and $26.6 \%$ were consuming fast foods as an evening snack. The study indicated a correlation between the body mass index and specific fast foods consumed such as burgers, grilled cheese, and sweet sandwiches, fried snacks, sweets, and confectionary. It is evidenced that such excessive intake of such High fats, sugar and salt foods is a predisposing factor for obesity among youngsters as found by Sami et al, Critchlow et al. $[18,19]$. The eateries should come up with healthier alternatives for the high fat high sugar foods and nutrition priming should be encouraged in fast food restaurants.

Table 5 revealed the most, moderate, and least influencing factors affecting choices among adolescents. It was observed that unexpectedly the food quality was the least influencing factor affecting food choices by $93 \%$ of adolescents. The lack of awareness on quality attributes of food, food safety aspects of foods could be the likely reason. A study by Gavaravarapu et al. [20] showed a lack of food quality and safety awareness among adolescents, especially the lack of food safety knowledge related to snacks foods.

The table 6 revealed the factor analysis results. Out of the thirteen factors, five factors were extracted through the principal component analysis. It was observed that the taste of the fast food and advertising contributed to $17.56 \%$ of the variance. Lack of time and quick service accounted for $10.06 \%$ of the variance. These results are comparable to one of the Indian study by Khongrangjem et al. [21] which stated taste and time limitations as driving factors for consumption of fast foods. It was observed that the time limitation and ease of consumption were found as the most influential factors by $75 \%$ of adolescents. The reasons could be the ready availability and deliverability of these items such as burgers or pizzas found in food joints compared to the traditional food items. Also, it is found that these items are easy to carry and simple to eat in the day-to-day routine compared to the conventional Indian food items consumed. The factor analysis results can serve as useful evidence for improving the eating behaviours of adolescents through targeted nutrition education interventions

\section{Conclusion}

Based on the results obtained from the study, it is concluded that the prominent attribute of fast food like taste along with the overall food environment which includes the advertising, branding, marketing, ambience, food quality, affordability provided by the fast food industry are the driving factors for fast food intake among adolescents. The study showed a significant correlation between the BMI, and consumption of burgers, grilled cheese and sweet sandwiches, fried snacks, sweets and confectionary. This calls for several nutrition interventional strategies to address the solutions towards factors identified for fast food consumption.

\section{Strength and Limitations}

The sample size for the study was good $(n=219)$ and represented the urban teens. The study provides an insight into social, psychological and economic determinants contributing towards fast food consumption. The study also has a few limitations. Being a cross sectional study, the results may not be generalised. There is a possibility of recall bias as the fast food consumption data were self-reported. 


\section{REFERENCES}

[1] UNFPA, A. "Profile of Adolescents and Youth in India," Census of India and United Nations Population Fund-India, 2014.https://india.unfpa.org/en/publications/profile-adoles cents-and-youth-india

[2] Mulla., Najnin R., Mahesh B., Chendake., Namrata C., Mohite.,Samir K., Choudhari., "Food consumption patterns among adolescents and their relation with obesity," Journal of Critical Reviews vol.7, no.8, pp.1906-1911, 2020. http://www.jcreview.com/fulltext/197-1594970140.pdf

[3] De Vogli., Roberto., Anne Kouvonen., David Gimeno., "The influence of market deregulation on fast food consumption and body mass index: a cross-national time series analysis," Bulletin of the World Health Organization, vol.92, pp. 99-107A, 2014. DOI: https://doi.org/10.2471/B LT.13.120287

[4] Manual., A, "Dietary guidelines for Indians," National Institute of Nutrition, Hyderabad, India second edition, pp.89-117, 2011. https://www.nin.res.in/downloads/Dietar yGuidelinesforNINwebsite.pdf

[5] Johnson., Sapna., Ramakant Sahu., Poornima Saxena., H. B. Mathur., H. C. Agarwal., "Nutritional analysis of junk food," Centre for Science and Environment, vol.1, pp.1-23, 2012. DOI: https://citeseerx.ist.psu.edu/viewdoc/download ?doi=10.1.1.233.1942\&rep=rep1\&type $=$ pdf

[6] Martin., Laura., Linda Bauld., Kathryn Angus., "Rapid evidence review: the impact of promotions on high fat, sugar and salt (HFSS) food and drink on consumer purchasing and consumption behaviour and the effectiveness of retail environment interventions, " Edinburgh: NHS Health Scotland, 2017. https://www.storre.stir.ac.uk/bitstream/1893/26290/1/Marti n\%20et\%20al\%202017_NHSHS_PromotionsOnHFSSFoo dDrink.pdf

[7] Noura M S Eid., Abeer AlJahdali., Eram Albajri., Manal Naseeb, "Childhood Obesity and Quality of Meals: The Saudi School Meal and Home Meal Study SSMHMS - A Cross Sectional Study," Journal of Food and Nutrition Research, vol 6(4), pp.250-255, 2018; DOI: $10.12691 /$ jfnr-6-4-7

[8] Gupta., Sabrina S., Helena Teede., and Rosalie Aroni., "Spicing up your advice for South Asian and Anglo-Australians with type 2 diabetes and CVD: Do cultural constructions of diet matter?," Appetite vol.120, pp.679-697, 2018. DOI: https://doi.org/10.1016/j.appet.20 17.10.007

[9] Zalewska., Magdalena., Elżbieta Maciorkowska., "Selected nutritional habits of teenagers associated with overweight and obesity," PeerJ 5, pp. e3681, 2017. DOI: https://doi.org/10.7717/peerj.3681

[10] Shaikh., Zakirhusain., Rambha Pathak., "Revised Kuppuswamy and BG Prasad socio-economic scales for 2016," International Journal of Community Medicine and Public Health, vol. 4(4), pp.997-999, 2017. DOI: http://dx.doi.org/10.18203/2394-6040.ijcmph20171313

[11] ALFaris., Nora A., Jozaa Z., Al-Tamimi., Moneera O., Al-Jobair., Naseem M. Al-Shwaiyat., "Trends of fast food consumption among adolescent and young adult Saudi girls living in Riyadh," Food \& Nutrition Research, vol.59, no.1, pp.26488, 2015. DOI: http://dx.doi.org/10.3402/fnr.v59.26 488

[12] Joseph, Nitin., Maria Nelliyanil., Raghavendra Babu YP., Sharada Rai., Shashidhar M., Kotian., Tanima Ghosh.,Manisha Singh., "Fast food consumption pattern and its association with overweight among high school boys in Mangalore city of southern India," Journal of clinical and diagnostic research: JCDR, vol.9, no.5, pp.LC13, 2015. DOI: $10.7860 / J C D R / 2015 / 13103.5969$

[13] Henry., Christiani Jeyakumar., Bhupinder Kaur., Rina Yu Chin Quek., "Are Asian foods as "fattening" as western-styled fast foods?," European journal of clinical nutrition, vol.74, no.2, pp.348-350, 2020. DOI: https://doi.org/10.1038/s41430-019-0537-3

[14] Vaida Naheed., "Prevalence of fast food intake among urban adolescent students," The international journal of engineering and science, vol.2, no.1, pp.353-359, 2013. http://theijes.com/papers/v2-i1/BC02103530359.pdf

[15] Czoli.,Christine D., Elise Pauzé., Monique Potvin Kent., "Exposure to food and beverage advertising on television among Canadian adolescents, 2011 to 2016," Nutrients, vol.12, no.2, pp.428, 2020. https://www.mdpi.com/2072-6 $643 / 12 / 2 / 428 / p d f$

[16] Molenaar., Annika. Wei Yee Saw., Linda Brennan., Mike Reid., Megan SC Lim., Tracy A., McCaffrey., "Effects of Advertising: A Qualitative Analysis of Young Adults' Engagement with Social Media About Food," Nutrients, vol.13, no.6, pp.1934, 2021. https://www.mdpi.com/2072$6643 / 13 / 6 / 1934 / p d f$

[17] Shree, Vijay., R. R. Prasad., Sanjay Kumar., Setu Sinha., Sanjay Kumar Choudhary., "Study on consumption of fast food among medical students of IGIMS, Patna," International Journal of Community Medicine and Public Health, vol.5, no.7, pp.2750-2754, 2018. DOI: http://dx.doi.org/10.18203/2394-6040.ijcmph20182416

[18] Sami Rokayya., T. Bushnaq., N. Benajiba., M. Helal., "FOOD CONSUMPTION AND LIFESTYLE HABITS AMONG UNIVERSITY STUDENTS IN SAUDI ARABIA," African Journal of Food, Agriculture, Nutrition \& Development, vol.21, no.3, pp.17711-17726, 2021. DOI: https://doi.org/10.18697/ajfand.98.20245

[19] Critchlow., Nathan., Linda Bauld., Christopher Thomas., Lucie Hooper., Jyotsna Vohra., "Awareness of marketing for high fat, salt or sugar foods, and the association with higher weekly consumption among adolescents: a rejoinder to the UK Government's consultations on marketing regulation," Public health nutrition, vol.23, no.14 pp.2637-2646, 2020. DOI: 10.1017/S1368980020000075

[20] Gavaravarapu SR, Vemula SR, Rao P, Mendu VV, Polasa $\mathrm{K}$. Focus group studies on food safety knowledge, perceptions, and practices of school-going adolescent girls in South India. Journal of nutrition education and behavior. 2009 Sep 1;41(5):340-6. https://doi.org/10.1016/j.jneb.200 8.12.003

[21] Khongrangjem., Tenneychell., Sushma Marita Dsouza., Priya Prabhu., Vijay Basappa Dhange., Vrindha Pari., Sunil Kumar Ahirwar., Kumar Sumit., "A study to assess the knowledge and practice of fast food consumption among 
Pre-University students in Udupi Taluk, Karnataka, India," Clinical Epidemiology and Global Health, vol. 6, no.4, pp.172-175, 2018. DOI: https://doi.org/10.1016/j.cegh.201 7.11.003 